Made available courtesy of Botanical Society of America: http://www.botany.org/

***Reprinted with permission. No further reproduction is authorized without written permission from the Botanical Society of America. This version of the document is not the version of record. Figures and/or pictures may be missing from this format of the document.***

American Journal of Botany 79(10): 1108-1112. 1992.

\title{
CARBON INTEGRATION IN TWO PLANTAGO SPECIES ${ }^{1}$
}

\author{
Elizabeth P. LaCeY ${ }^{2}$ and C. Marshall \\ Department of Biology, University of North Carolina, Greensboro, North Carolina 27412; and \\ School of Biological Sciences, University College of North Wales, Bangor, Gwynedd LL57 2UW, UK
}

\begin{abstract}
We measured the pattern of export of ${ }^{14} \mathrm{C}$-assimilate from reproductive spikes and leaves subtending spikes in Plantago aristata and $P$. virginica. In $P$. aristata, little ${ }^{14} \mathrm{carbon}$ was exported to any other reproductive metamer (leaf + associated spike) from the leaf subtending a flowering spike. In $P$. virginica a large amount was exported. Thus, like clonal species, rosette species can vary in patterns of carbon integration among the repeated morphological subunits comprising an individual. When considered in the context of other studies, these data suggest that comparisons of carbon integration in species differing in morphological complexity would be useful in trying to understand the evolution of patterns of carbon integration in plants.
\end{abstract}

Most studies addressing the carbon integration of repeating morphological subunits in naturally growing plants have focused on clonal species, those producing multiple ramets (e.g., Pitelka and Ashmun, 1985; Hutchings and Bradbury, 1986; Slade and Hutchings, 1987; Marshall, 1990; Schmid, 1990; Alpert, 1991; Caraco and Kelly, 1991). These studies have been motivated not only by an interest in the evolution of patterns of carbon integration/ independence among ramets, but also by a desire to understand the evolution of patterns of integration among morphological subunits, or modules, in general. Ramets have received the greatest attention because with few exceptions they are the only morphological subunits to have both roots and shoots. Thus, unlike branches or metamers (sensu White, 1984) on branches, ramets of clonal species can range from complete integration to complete independence. Theoretically, however, ramets, branches, and metamers could each show different degrees of integration among species, populations, and/or individuals, and their patterns of integration may evolve in different ways. Thus, studies of integration for each type of morphological subunit are needed.

In contrast to ramets, information about integration patterns for branches and metamers in species from natural plant populations is limited. A few experimental studies involving leaf removals provide evidence for the physiological independence of branches of some trees (Janzen, 1976; Stephenson, 1980; Bertin, 1982; Marquis, 1988), although not subarctic birches (e.g., Tuomi et al., 1989). For herbaceous annuals, Thomas and Watson (1988) found that branches of Capsicum annuum functioned independently of each other, while Garrish and Lee (1989) found little evidence for physiological independence of metamers on branches of Cassia fasciculata. Because we have found no information about integration patterns within rosette species, we decided to examine carbon integration among the simplest morphological units, metamers, on

\footnotetext{
${ }^{1}$ Received for publication 8 July 1991; revision accepted 26 June 1992.

The authors thank J. Antonovics, C. Augspurger, J. Schmitt, and D. Simberloff for comments on an earlier draft of this manuscript; the University College of North Wales (UCNW), Bangor, UK for providing assistance and facilities for this experiment; the University of North Carolina-Greensboro for giving EPL the opportunity to visit UCNW; and J. L. Harper for hospitality during EPL's visit to UCNW.

2 Author for correspondence.
}

two species of Plantago. Our observations suggest new questions about the evolution of patterns of integration, questions that could not be envisioned by focusing solely on species that resemble each other in morphological construction.

\section{STUDY SPECIES AND METHODS}

We chose two species of Plantago: $P$. virginica $\mathrm{L}$. and $P$. aristata Michx. (Plantaginaceae)(Fig. 1). They resemble each other in several ways. Both are winter annuals that grow as rosettes from a thin taproot in disturbed habitats of the eastern United States (Johnson, 1981). Axillary meristems differentiate into reproductive spikes. For the purpose of this study, the two species differ morphologically in two ways. Early in P. aristata's development, one to several axillary meristems develop into lateral branches (also called lateral rosettes) rather than directly into reproductive spikes. Later in development, the main stem and the lateral branches produce spikes. In contrast, $P$. virginica seldom branches. Additionally, $P$. aristata produces green leafy bracts subtending the flowers on the reproductive spike. $P$. virginica lacks bracts (Johnson, 1981; Lacey, unpublished data). We examined the carbon integration of shoot metamers in these species by measuring the patterns of assimilation and translocation of radioactive carbon within and among metamers on the shoot of the main rosette. We operationally defined a shoot metamer as a leaf plus the reproductive spike arising from that leaf's axillary meristem. As both species form rosettes, internodes belonging to different metamers constituted little of total plant biomass and were difficult to separate. Therefore, all internodes were combined with the apical meristem and referred to as "apex" tissue.

Seeds of both species were collected from a recently disturbed field in Durham, North Carolina during the summer and stored in paper bags in the lab for $19 \mathrm{mo}$. Plants were then sown in pots containing John Innes No. 1 potting compost (a commercial horticultural compost of loam, peat, and sand at 7:4:2 parts by volume with added nutrient supplement) and were subsequently transplanted and grown individually in pots in a heated greenhouse. The minimum day and night temperatures were 18 and $16 \mathrm{C}$, respectively. The maximum temperatures fluctuated depending on the weather but did not exceed $25 \mathrm{C}$. For the first $8 \mathrm{wk}$ of growth the plants received 


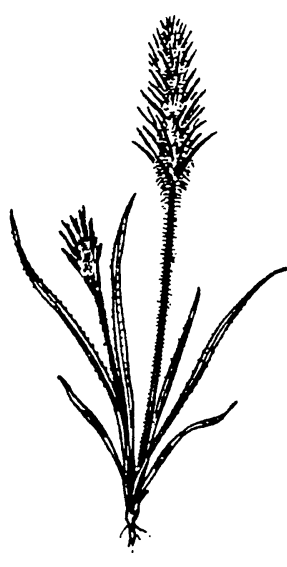

P. aristata

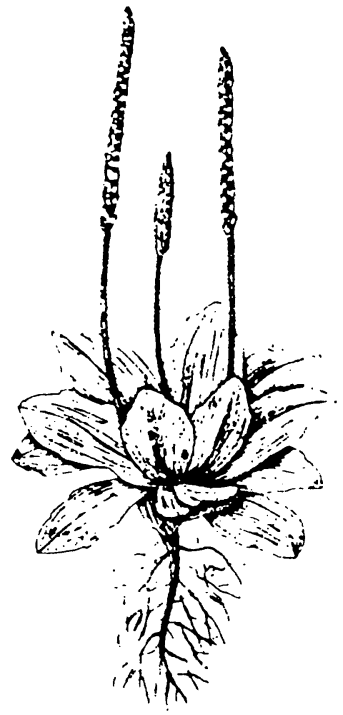

P. virginica

Fig. 1. The experimental species.

supplementary lighting from 400 -W high pressure sodium lamps with a minimum photoperiod of $14 \mathrm{hr}$. After that time the lights were not needed to provide $14 \mathrm{hr}$ daylength. The pots were watered daily. The pattern of plant growth and flowering closely resembled that observed in fieldgrown plants. After 15 and 19 wk (reflecting the natural difference in flowering time), flowering plants of $P$. virginica and $P$. aristata, respectively, were selected for uniform development (e.g., similar size and number and maturity of inflorescences) and then randomly assigned to one of seven treatments for exposure to ${ }^{14} \mathrm{CO}_{2}$ (Table 1). We did not have enough individuals of $P$. aristata to include it in treatment 6 . Individuals of $P$. virginica had from three to eight reproductive spikes per plant, and those of $P$. aristata had from three to five.

For treatment 1 , the assimilatory activity of leaves and flowering spikes of individual plants was assessed by whole plant exposure to ${ }^{14} \mathrm{CO}_{2}$ for $15 \mathrm{~min}$. Plants were transferred from the greenhouse to a controlled environment room ( $17 \mathrm{C}$; fluorescent lights at $150 \mu$ Einsteins $\mathrm{m}^{-2} \mathrm{sec}^{-1}$ ) $2 \mathrm{hr}$ before treatment. They were sealed in a large perspex chamber, and ${ }^{14} \mathrm{CO}_{2}$ was generated within the chamber by the addition of dilute $\mathrm{HCl}$ to $3.7 \mathrm{MBq}$ of an aqueous solution of $\mathrm{Na}_{2}{ }^{14} \mathrm{CO}_{3}\left(21.8 \mathrm{MBq} \mathrm{mg}^{-1}\right)$. Fans stirred the air within the chamber. After an assimilation period of $15 \mathrm{~min},{ }^{14} \mathrm{CO}_{2}$ was pumped from the chamber and the plants were rapidly harvested by separation into component parts. Particular attention was given to the isolation and identification of each shoot metamer. The separated components were then dried at $70 \mathrm{C}$ and weighed. Five replicates of $P$. virginica and three of $P$. aristata were exposed to ${ }^{14} \mathrm{CO}_{2}$.

Treatments 2-7 (Table 1) were performed in the greenhouse to measure the pattern of distribution of ${ }^{14} \mathrm{C}$-assimilate from flowering spikes at different developmental stages and from leaves subtending spikes at these stages.
TABLE 1. Experimental treatments to measure the assimilation and transport of radiocarbon by $\mathrm{Plantago}$ aristata and $\mathrm{P}$. virginica

\begin{tabular}{|c|c|c|}
\hline Treatment & Part exposed to radiocarbon & $\begin{array}{l}\text { Developmental stage } \\
\text { of reproductive spike }\end{array}$ \\
\hline 1 & Whole plant & - \\
\hline 2 & Leaf & $\begin{array}{l}\text { Early flowering: (peduncle } \\
\text { partially elongated, no } \\
\text { open flowers) }\end{array}$ \\
\hline 3 & $\begin{array}{l}\text { Inflorescence ( } P \text {. aristata } \\
\text { only) }\end{array}$ & $\begin{array}{l}\text { Early flowering: (peduncle } \\
\text { partially elongated, no } \\
\text { open flowers) }\end{array}$ \\
\hline 4 & Leaf & $\begin{array}{l}\text { Mid-flowering inflorescence: } \\
\text { (peduncle elongated, only } \\
\text { lower flowers open) }\end{array}$ \\
\hline 5 & Inflorescence & $\begin{array}{l}\text { Mid-flowering inflorescence: } \\
\text { (peduncle elongated, only } \\
\text { lower flowers open) }\end{array}$ \\
\hline 6 & Leaf ( $P$. virginica only) & $\begin{array}{l}\text { Partially developed infruc- } \\
\text { tescence (all flowers past } \\
\text { anthesis) }\end{array}$ \\
\hline 7 & $\begin{array}{l}\text { Inflorescence (P. virginica } \\
\text { only) }\end{array}$ & $\begin{array}{l}\text { Partially developed infruc- } \\
\text { tescence (all flowers past } \\
\text { anthesis) }\end{array}$ \\
\hline
\end{tabular}

For each treatment we enclosed the designated leaf or spike in a polyester chamber and produced ${ }^{14} \mathrm{CO}_{2}$ within the chamber by adding $\mathrm{HCl}$ to a 5- $\mu$ ldroplet of $\mathrm{Na}_{2}{ }^{14} \mathrm{CO}_{3}$ $(74 \mathrm{kBq})$. We removed the chambers after an assimilation period of $20 \mathrm{~min}$ and harvested the plants after $24 \mathrm{hr}$. Roots were washed from compost and each plant was separated into component parts as previously described and dried at $70 \mathrm{C}$.

To determine the distribution of radioactive carbon, we both autoradiographed plants and then measured radiocarbon quantitatively by liquid scintillation counting. Autoradiographs of three replicates per treatment were prepared by exposing mounted plants to Kodak direct exposure film for a period of $4 \mathrm{~d}$. The radiocarbon in each part of $P$. virginica was measured quantitatively using four additional plants per treatment that were treated in the same way but not autoradiographed. Because we had fewer individuals of $P$. aristata available for each treatment, we measured the radiocarbon quantitatively in the plants that we had autoradiographed. For our quantitative measurements, we combusted samples in oxygen using a Harvey Biological Oxidizer OX400. The ${ }^{14} \mathrm{CO}_{2}$ liberated was trapped in a scintillation cocktail containing $27 \%$ phenylethylamine, $27 \%$ ethanol, and $46 \%$ NE233 liquid scintillator (Nuclear Enterprises Ltd.) and counted in a LKB Rackbeta II liquid scintillation counter. These methods closely follow those described by Colvill and Marshall (1984).

\section{RESULTS}

The pattern of ${ }^{14} \mathrm{CO}_{2}$ uptake differed between the two species (Fig. 2) and matched closely the relative distribution of photosynthetic surfaces. The spikes assimilated much more ${ }^{14} \mathrm{CO}_{2}$ in $P$. aristata than in $P$. virginica. In the latter species, which lacks green bracts, the spikes (inflorescences including peduncles) accounted for only $5.5 \%$ of the total ${ }^{14} \mathrm{CO}_{2}$ uptake by the plant (Fig. 2a), and uptake by the spike was similar for different aged meta- 
(a) P. virginica

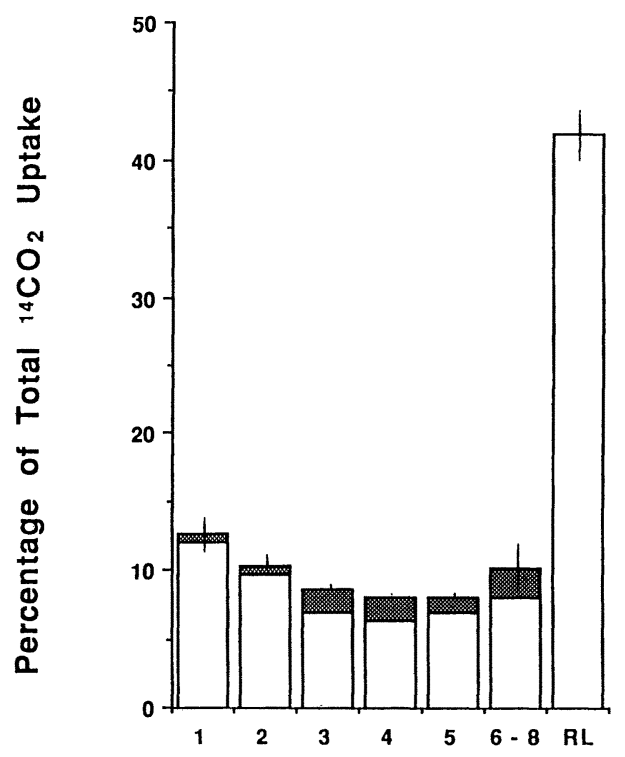

(b) P. aristata

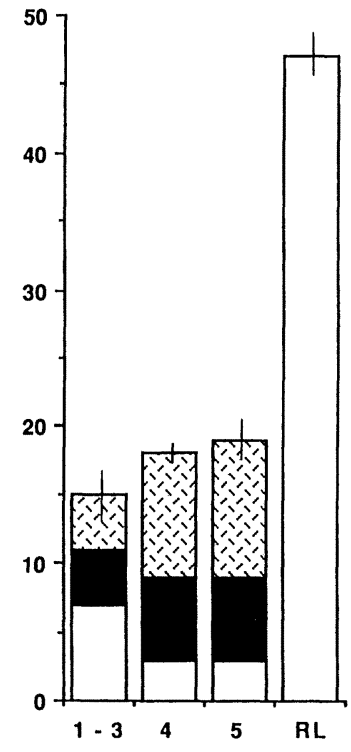

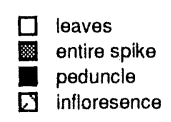

Metamer

Fig. 2. ${ }^{14} \mathrm{CO}_{2}$ fixation by individual metamer as $\%$ of total ${ }^{14} \mathrm{CO}_{2}$ uptake for the whole plant (Treatment 1). a) Plantago virginica; b) P. aristata. Vertical bar indicates $2 \times$ (standard error) of entire column. Numbers $1-8=$ reproductive metamers in order of increasing age; $\mathrm{RL}=$ nonreproductive metamers (i.e., remaining rosette leaves).

mers. In $P$. aristata, the flowers and leafy bracts of the spike, alone, accounted for $25 \%$ of the total plant uptake of ${ }^{14} \mathrm{CO}_{2}$. The entire spike including peduncle accounted for $42 \%$ of the total uptake (Fig. 2b). Uptake by the spike increased with metamer age. Within the two oldest reproductive metamers of $P$. aristata, i.e., the metamers having the most mature spikes, the spike accounted for $87 \%$ of the total uptake of ${ }^{14} \mathrm{CO}_{2}$. Correspondingly, the leaves of these metamers contributed little to total assimilatory capacity, in contrast to the leaves of $P$. virginica. In both species ${ }^{14} \mathrm{CO}_{2}$ uptake by the residual leaves, i.e., by leaves with no associated spikes, was close to $50 \%$ of the total uptake for the whole plant.

Reproductive metamers of $P$. aristata had about five times greater biomass than did those of $P$. virginica, yet the weight of the single leaf subtending the spike was very similar (i.e., the difference in weight was due to the spike). Assimilation expressed per unit weight suggests that the leaf is more effective than is the spike in fixing $\mathrm{CO}_{2}$, especially in $P$. virginica. However, because the two species were exposed to ${ }^{14} \mathrm{CO}_{2}$ separately, we do not have a direct measure of comparative photosynthetic ability.

The proportion of assimilate exported from treated leaves subtending spikes (Treatments $2,4,6$ ) was similar for both species $(\bar{X} \pm$ SE: $58.3 \pm 9.48$ and $47.9 \% \pm 8.10 \%$ for $P$. virginica and $P$. aristata, respectively). In both species the ${ }^{14} \mathrm{C}$-treated leaf exported a high proportion of assimilate to nonreproductive metamers of the rosette (Fig. 3). Also, the autoradiographs showed no movement of assimilate into lateral rosettes of $P$. aristata and no movement of assimilate from treated inflorescences to other parts of the plant in either species (Treatments 3, $5,7)$.
In spite of the above similarities, the two species did differ in their distribution of assimilate for the two flowering stages permitting comparison (Fig. 3). In $P$. virginica, from $38 \%$ to $50 \%$ was exported to other flowering metamers, particularly the inflorescence of the older adjacent metamer (Fig. 3b). In P. aristata, less than 5\% was exported to other metamers (Fig. 3a). Thus, the species differed markedly in the movement of labeled carbon among reproductive metamers.

The temporal changes in assimilate movement that were associated with spike development also differed between species. Within a metamer in $P$. virginica, the amount of assimilate moving from a leaf to its associated spike doubled from the time of spike appearance to the time of seed development. Two-thirds of the assimilate was found in the inflorescence by time of fruiting (Fig. 3b). This increased support did not occur at the expense of the adjacent metamer but rather reflected a drop in export to other spikes and the roots. In contrast, in $P$. aristata, the movement of assimilate from a leaf to its associated spike dropped by $60 \%$ from the time of spike emergence to flowering (Fig. 3a). The assimilate moved instead to the root system so that just over half of the total exported ${ }^{14} \mathrm{C}$-assimilate was transported to the roots by the midflowering stage. Autoradiographs visually confirmed all of our quantitative measurements.

\section{DISCUSSION}

Carbon translocation among morphological subunits of plants is often restricted; also, carbon pathways can vary greatly with developmental maturity of the plant (see review by Watson and Casper, 1984). Our study shows that 
(a) P. aristata

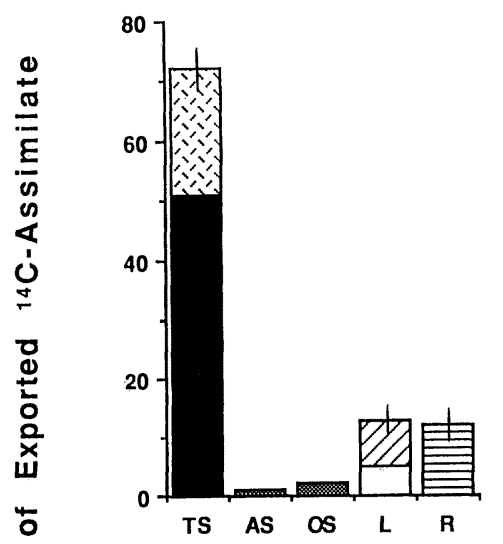

(b) P. virginica

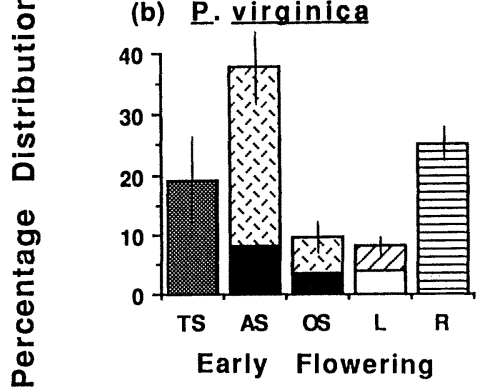

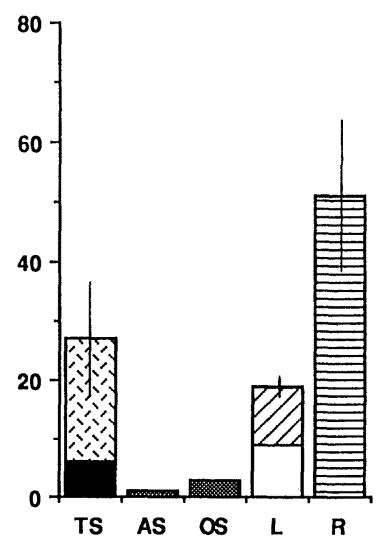

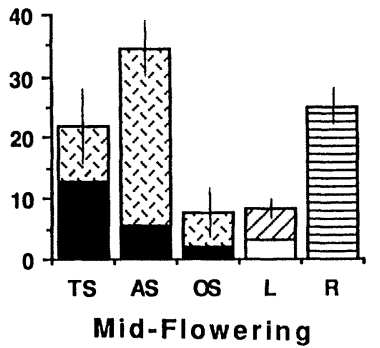

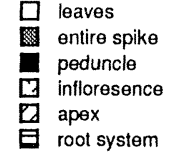

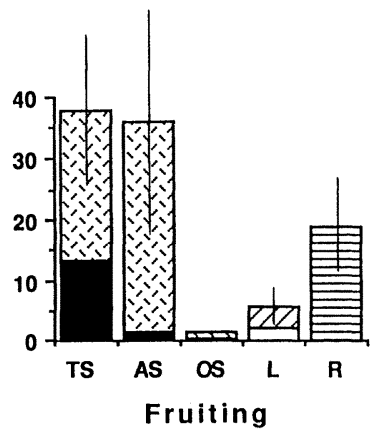

Part of Plant Importing $14 \mathrm{C}$-Assimilate

Fig. 3. Percentage distribution of ${ }^{14} \mathrm{C}$-assimilate exported to various parts of the plant from a radioactively treated leaf at early flowering, midflowering, or fruiting stage of development for its associated spike. a) Plantago aristata; b) P. virginica. Vertical bar indicates $2 \times$ (standard error) of entire column. TS $=$ spike associated with ${ }^{14} \mathrm{C}$-treated leaf; AS $=$ spike belonging to adjacent older flowering metamer; OS $=$ spikes belonging to other flowering metamers; $\mathrm{L}=$ shoot apex and leaves; $\mathrm{R}=$ root system.

both of these observations hold true for rosette species collected from natural populations. More interestingly, the study shows that rosette species can differ in their pattern of carbon translocation. Reproductive shoot metamers of $P$. virginica are linked directly to each other by pathways for carbon flow, and these pathways are heavily used, particularly up to fruiting time. The observation that carbon flow changes temporally reflects the changing pattern of sink demands during reproduction. In contrast, in $P$. aristata, very little carbon moves from one reproductive metamer to another. It is unlikely that this interspecific difference can be explained by differences in the developmental maturity of the two species at the time we measured carbon translocation. Both species resembled each other in terms of both the number of reproductive spikes per plant and the developmental stages of the metamers that we exposed to ${ }^{14} \mathrm{CO}_{2}$.

The interspecific difference is more likely explained by a difference in vascular pathways, which might more strongly restrict assimilate movement in P. aristata (i.e., by the absence of functional phloem), or by a difference in physiological factors regulating carbon flow (i.e., the source-sink relations). The latter explanation seems more plausible, in view of the additional local photosynthetic contribution of the inflorescence bracts to flower and seed development in $P$. aristata. If bracts can support local demand, one might expect leaves to be "freer" to export carbon elsewhere. Possibly the root system in $P$. aristata acts as an intermediary to shunt some resources from one shoot metamer to another, but even if it does, $P$. virginica still shows more direct functional integration than does P. aristata.

Our data show that the diversity of integration patterns previously observed at the ramet and branch levels also extend to the metamer level. Why this diversity exists is unclear. Most studies examining the selective advantages and disadvantages of carbon integration have focused on integration among ramets. So one can ask whether or not these same pressures influence integration among branches and metamers as well. For example, do selective pressures (e.g., that could arise from resource patchiness or herbivory) act upon more than one type of subunit, or are some selective pressures unique to a particular subunit? Additionally, do evolutionarily successful alterations in morphological complexity necessitate alterations in physiological independence of existing morphological subunits? For example, does an evolutionarily successful shift from a lower level of complexity (e.g., metameric, as in $P$. virginica) to a higher level (e.g., branch, as in $P$. aristata) need to be preceded by or occur with an increase in carbon independence of the simpler unit (e.g., the metamer). There are presently no studies that address these questions.

In conclusion, most previous studies addressing the evolution of patterns of integration in plants have focused on species that are similar in morphological organization, 
primarily clonal species. Because data now show that differences in integration patterns can be observed in all types of morphological subunits, attention should also be given to comparing patterns in closely related species differing in morphological complexity.

\section{LITERATURE CITED}

AlPERT, P. 1991. Nitrogen sharing among ramets increases clonal growth in Fragaria chiloensis. Ecology 72: 69-80.

BERTIN, R. I. 1982. The ecology of sex expression in red buckeye. Ecology 63: 445-456.

Caraco, T., AND C. K. Kelly. 1991. On the adaptive value of physiological integration in clonal plants. Ecology 72: 81-93.

Colvill, K. E., AND C. Marshall. 1984. Tiller dynamics and assimilate partitioning in Lolium perenne $\mathrm{L}$., with particular reference to flowering. Annals of Applied Biology 104: 543-557.

GARRISH, R. S., AND T. D. LEE. 1989. Physiological integration in Cassia fasciculata Michx.: inflorescence removal and defoliation experiments. Oecologia 81: 279-284.

HutchINGS, M. J., AND I. K. BRADBURY. 1986. Ecological perspectives on clonal perennial herbs. Bioscience 36: 178-182.

JANZEN, D. H. 1976. Effect of defoliation on fruit-bearing branches of the Kentucky coffee tree, Gymnocladus dioicus (Leguminosae). American Midland Naturalist 95: 474-478.

Johnson, M. F. 1981. Phrymaceae and Plantaginaceae in Virginia. Virginia Journal of Science 32: 12-16.

MARQUIS, R. J. 1988. Intra-crown variation in leaf herbivory and seed production in striped maple, Acer pensylvanicum L. (Aceraceae). Oecologia 77: 51-55.
MARSHALl, C. 1990. Source-sink relations of interconnected ramets. In J. van Groenendael and $\mathrm{H}$. de Kroon [eds.], Clonal growth in plants: regulation and function, 23-41. SPB Academic Publishing, The Hague, Netherlands.

PitelkA, J. F., AND J. W. Ashmun. 1985. Physiology and integration of ramets in clonal plants. In J. B. C. Jackson, L. W. Buss, and R. E. Cook [eds.], Population biology and evolution of clonal organisms, 399-435. Yale University Press, New Haven, CT.

Schmid, B. 1990. Some ecological and evolutionary consequences of modular organization and clonal growth in plants. Evolutionary Trends in Plants 4: 25-34.

Slade, A. J., AND M. J. Hutchings. 1987. Clonal integration and plasticity in foraging behaviour in Glechoma hederacea. Journal of Ecology 75: 1023-1036.

Stephenson, A. G. 1980. Fruit set, herbivory, fruit reduction and the fruiting strategy of Catalpa speciosa (Bignoniaceae). Ecology 61: $57-64$

Thomas, L. P., AND M. A. WATson. 1988. Leaf removal and the apparent effects of architectural constraints on development in Capsicum annuum. American Journal of Botany 75: 840-843.

TuOMI, J., T. Vuorisalo, P. Niemela, AND E. Houkioja. 1989. Effects of localized defoliations on female inflorescences in mountain birch, Betula pubescens ssp. tortuosa. Canadian Journal of Botany 67: 334-338.

WAtson, M. A., AND B. B. CASPER. 1984. Morphogenetic constraints on patterns of carbon distribution in plants. Annual Review of Ecology and Systematics 15: 233-258.

White, J. 1984. Plant metamerism. In R. Dirzo and J. Sarukhan [eds.], Perspectives on plant population ecology, 15-47. Sinauer, Sunderland, MA. 